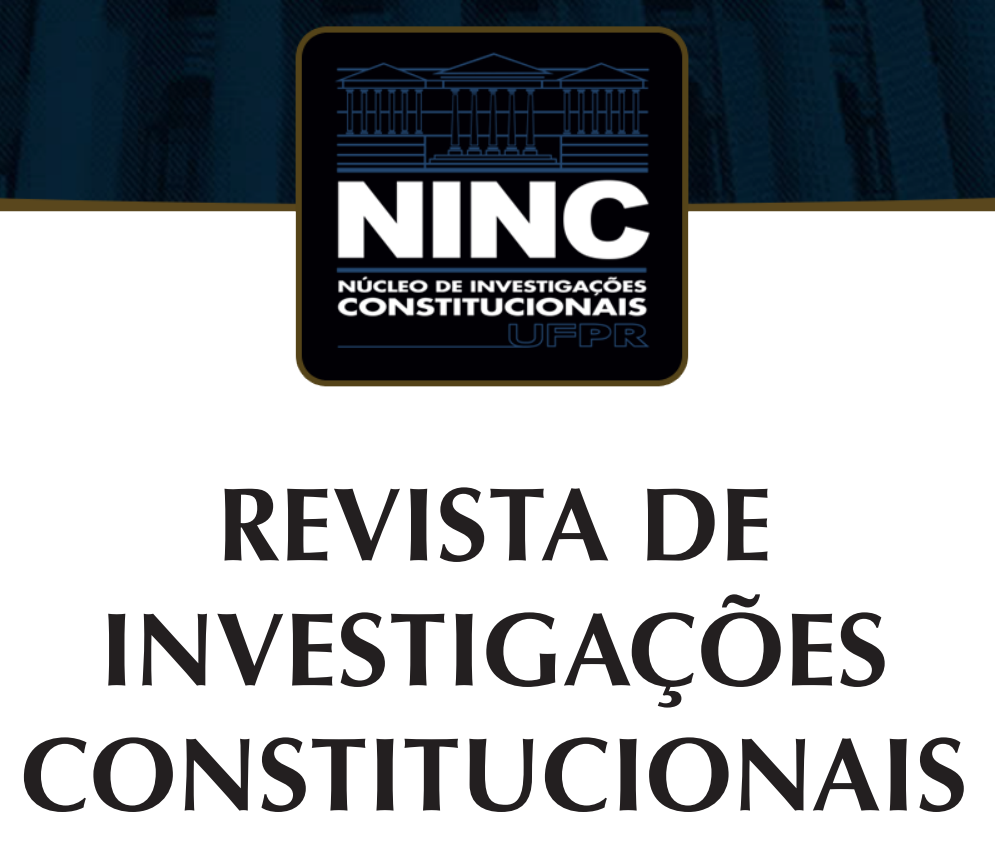

JOURNAL OF CONSTITUTIONAL RESEARCH

vol. 6 | n. 2 | maio/agosto 2019 | ISSN 2359-5639 | Periodicidade quadrimestral Curitiba | Núcleo de Investigações Constitucionais da UFPR | www.ninc.com.br 

Licensed under Creative Commons

\section{A Revista de Investigações Constitucionais é indexada na Redalyc}

\section{The Journal of Constitutional Research is covered in Redalyc}

\section{DANIEL WUNDER HACHEM ${ }^{1, *}$}

' Universidade Federal do Paraná (Brasil) danielhachem@gmail.com http://orcid.org/0000-0001-8519-8420

\section{LUZARDO FARIA ${ }^{1, *+}$}

' Universidade Federal do Paraná (Brasil) farialuzardo@hotmail.com http://orcid.org/0000-0001-7330-2649

Seguindo o propósito de indexar a Revista de Investigações Constitucionais nas principais bases de dados, fontes de informação e diretórios de pesquisa nacionais e internacionais, é com grande alegria que anunciamos a indexação do periódico na Redalyc - Red de Revistas Cientificas de América Latina y el Caribe, España y Portugal. Trata-se de uma importante base de dados bibliográfica e biblioteca digital de revistas de acesso aberto, voltada ao propósito de difundir o conhecimento científico produzido nos países ibero-americanos e dar-lhes maior visibilidade.

Com mais essa conquista, concluímos o objetivo traçado inicialmente, quando da concepção da revista, de obter a sua inclusão nos quatro principais indexadores

Como citar esse editorial/How to cite this editorial: HACHEM, Daniel Wunder; FARIA, Luzardo. A Revista de Investigações Constitucionais é indexada na Redalyc. Revista de Investigações Constitucionais, Curitiba, vol. 6, n. 2, p. 235-237, maio/ago. 2019. DOI: 10.5380/rinc.v6i2.70565.

*Editor-Chefe da Revista de Investigações Constitucionais. E-mail: danielhachem@gmail.com.

** Editor-Adjunto da Revista de Investigações Constitucionais. E-mail: farialuzardo@hotmail.com. 
no cenário internacional: Scopus, Web of Science, SciELO e Redalyc. Novamente, nossa profunda gratidão é devida a todos aqueles que contribuíram para o êxito deste ciclo, aí incluídos os membros do Conselho Editorial, pareceristas, autores e leitores da Revista de Investigações Constitucionais.

Neste número, o segundo do ano de 2019, publicamos artigos em 4 idiomas (inglês, francês, espanhol e português), de autores vinculados a 12 instituições de ensino superior de 4 países diferentes: Áustria, Chile, Espanha e de 6 diferentes unidades federativas da República Federativa do Brasil, com representação das regiões Sul, Sudeste, Centro-Oeste e Nordeste: Rio Grande do Sul, Santa Catarina, São Paulo, Minas Gerais, Distrito Federal e Pernambuco. Dos trabalhos publicados, $90 \%$ são de Professores Doutores, 60\% redigidos em língua estrangeira, 30\% dos artigos possuem entre seus autores pesquisadores afiliados a instituições estrangeiras e $100 \%$ dos autores são exógenos ao Estado do Paraná. São eles:

- Constitutional neutrality: an essay on the essential meaning of freedom of speech

\section{João dos Passos Martins Neto}

Professor dos Cursos de Graduação e Pós-Graduação em Direito da Universidade Federal de Santa Catarina (Florianópolis-SC, Brasil)

- Anti-racism legislation in Brazil: the role of the Courts in the reproduction of the myth of racial democracy

\section{Marta Rodriguez de Assis Machado}

Professor at the Getulio Vargas Foundation School of Law (São Paulo-SP, Brasil)

\section{Márcia Regina de Lima Silva}

Professor at University of Sao Paulo (São Paulo-SP, Brasil)

\section{Natália Neris da Silva Santos}

PhD Candidate at University of Sao Paulo (São Paulo-SP, Brasil)

- The applicability of the Internet of Things (IOT) between fundamental rights to health and to privacy

\section{Mateus de Oliveira Fornasier}

Professor do Programa de Pós-Graduação Stricto Sensu (Mestrado e Doutorado) em Direitos Humanos da Universidade Regional do Noroeste do Estado do Rio Grande do Sul (Unijuí-RS Brasil)

- L'accès indirect des citoyens aux cours constitutionnelles en Allemagne, Brésil et France

\section{Carolina Alves das Chagas}

Doctorante et assistante de recherche et d'enseignement à l'Université de Graz (Áustria) 
- La gratuidad de los derechos prestacionales como derechos humanos: una propuesta para su ponderación y otorgamiento

\section{Carlos Manuel Rosales}

Doctor en derecho por la Universidad de Chile (Santiago, Chile)

- El nuevo Pilar Europeo de Derechos Sociales: ¿hacia un fortalecimiento real de la dimensión social de la Unión Europea?

\section{Lucía Casado Casado}

Profesora Titular de Derecho Administrativo de la Universidad Rovira i Virgili (Tarragona, España)

- Filtros de acesso às Cortes Constitucionais: a Questão Prioritária de Constitucionalidade e os filtros de acesso ao Conselho Constitucional francês

\section{Luiz Henrique Diniz Araújo}

Professor da Faculdade Boa Viagem/Devry (Recife/PE, Brasil)

- Contencioso eleitoral em tempos de judicialização da política: a disputa no Supremo e o Supremo na disputa

\section{Eduardo Borges Espíndola Araújo}

Mestre em Direito, Estado e Constituição pela Universidade de Brasília (Brasília-DF, Brasil)

\section{Júlia Maurmann Ximenes}

Professora da Pós-Graduação e do Mestrado em Direito Constitucional do Instituto Brasiliense de Direito Público (Brasília-DF, Brasil)

- Teoria do ato administrativo nos trinta anos da Constituição de 1988: o que mudou?

\section{Ricardo Marcondes Martins}

Professor de Direito Administrativo da Faculdade de Direito da Pontifícia Universidade Católica de São Paulo (São Paulo-SP, Brasil)

- Filtros de acesso às Cortes Constitucionais: a Questão Prioritária de Constitucionalidade e os filtros de acesso ao Conselho Constitucional francês

\section{Emilio Peluso Neder Meyer}

Professor Adjunto de Direito Constitucional da Faculdade de Direito da Universidade Federal de Minas Gerais (Belo Horizonte-MG, Brasil)

Esperamos que os artigos selecionados para esta edição constituam importante fonte de pesquisa para os estudiosos do Direito Constitucional, firmes na expectativa de continuarmos recebendo submissões marcadas pela profundidade teórica das análises realizadas. 